San Jose State University

SJSU ScholarWorks

Master's Projects

Master's Theses and Graduate Research

$5-1-2004$

\title{
Investigating the Correlation Between Nurses' Spiritual Well-Being and Spiritual Care Perspectives
}

Marion Lieber Reyes

San Jose State University

Follow this and additional works at: https://scholarworks.sjsu.edu/etd_projects

Part of the Other Nursing Commons

\section{Recommended Citation}

Reyes, Marion Lieber, "Investigating the Correlation Between Nurses' Spiritual Well-Being and Spiritual Care Perspectives" (2004). Master's Projects. 810.

DOI: https://doi.org/10.31979/etd.bhf4-m5gp

https://scholarworks.sjsu.edu/etd_projects/810

This Master's Project is brought to you for free and open access by the Master's Theses and Graduate Research at SJSU ScholarWorks. It has been accepted for inclusion in Master's Projects by an authorized administrator of SJSU ScholarWorks. For more information, please contact scholarworks@sjsu.edu. 


\section{SAN JOSE STATE UNIVERSITY \\ SCHOOL OF NURSING}

\section{MASTER'S PROGRAM PROJECT OPTION (PLAN B) PROJECT SIGNATURE FORM}

STUDENT NAME

Manion Reyes

SEMESTER ENROLLED Spring 2005

TITLE OF PROJECT

Investigating the correlation between

nurses' spiritual well being and spivitual

cane peisfectives.

NAME OF JOURNAL Journal of Holistic nursing

The project and manuscript have been successfully completed and meet the standards of the School of Nursing at San Jose State University. The project demonstrates the application of professional knowledge, clinical expertise, and scholarly thinking. An abstract of the project and two copies of the manuscript are attached.

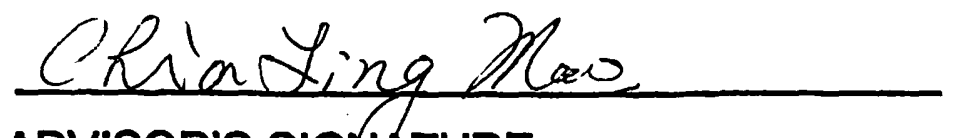

ADVISOR'S SIGNATURE

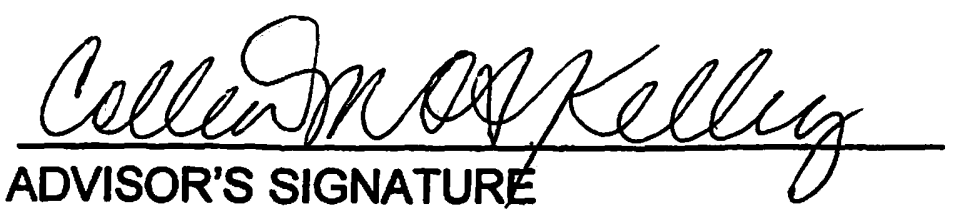

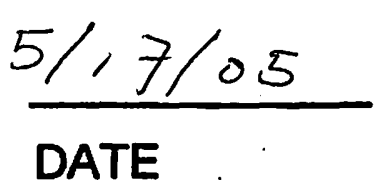

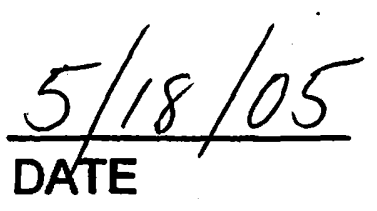

Please submit this form to the Graduate Coordinator. Attach abstract, two copies of the manuscript, and documentation of submission to the journal (i.e., postal receipt). 
Marion Licher Reyes, RN

Receipt of Manuscript Submission
NURS 297: Master's Project

Spring 2005

Research: Investigating the Correlation Between Nurses' Spiritual Well-Being and Spiritual Care Perspectives.

\footnotetext{
VALLEY PLAZA POST OFFICE

NORTH HOLLYWOOD, California 916063232

05/17/2005 $10: 40: 33$ AM

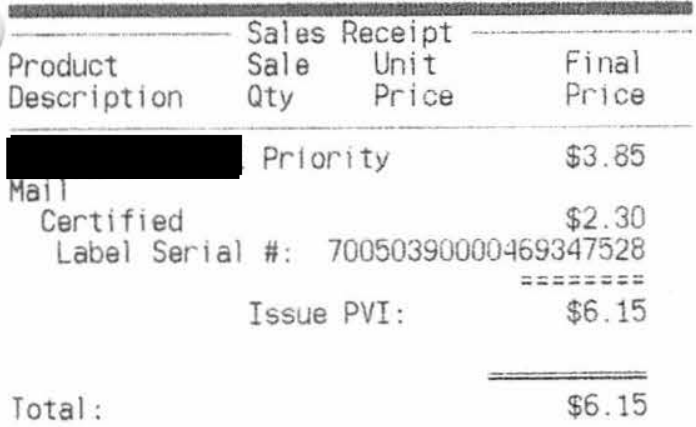

Paid by:

Debit Card

Account

Approval \#:

Transaction \#:

23903600518

Receipt\#:

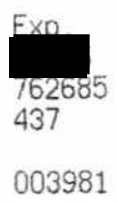

$\$ 6.15$

Bill\#: 1000301092358

Clerk: 11

- All sales final on stamps and postage. Refunds for guaranteed services only.

Thank you for your business. Customer Copy
}

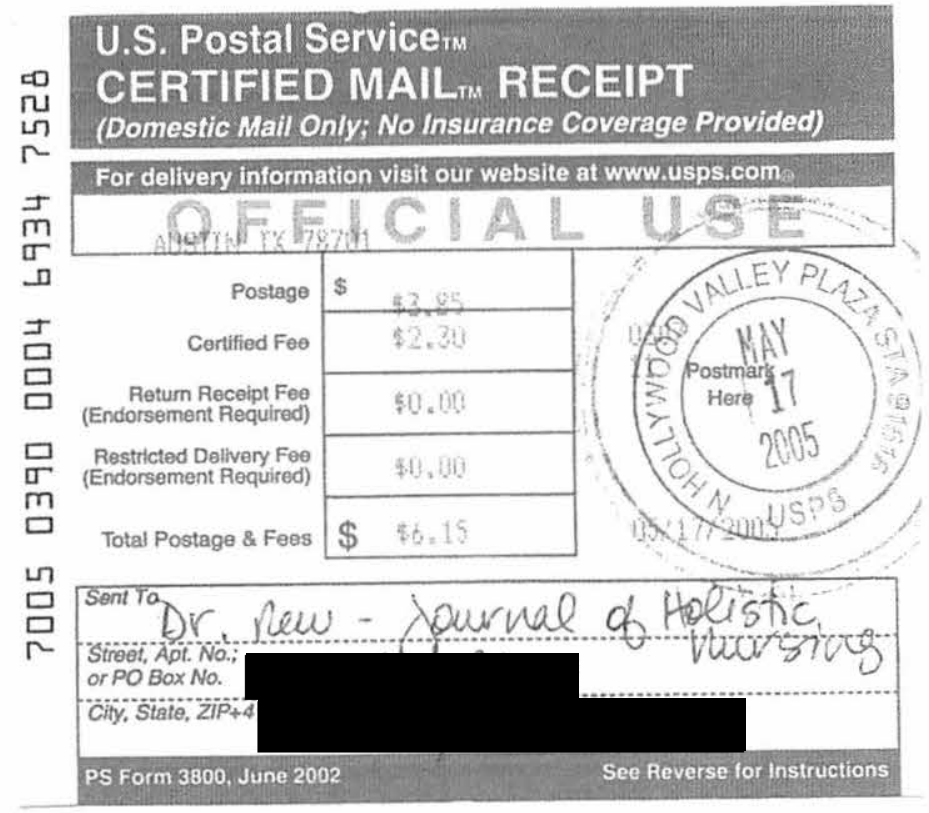


Running head: SPIRITUAL WELL-BEING AND SPIRITUAL CARE

\author{
INVESTIGATING THE CORRELATION BETWEEN NURSES' \\ SPIRITUAL WELL-BEING AND SPIRITUAL CARE PERSPECTIVES
}

\author{
A Research Paper Presented to \\ The Faculty of the School of Nursing \\ San Jose State University \\ In Partial Fulfillment of the \\ Requirements for the Course \\ NURS 297: Master's Project
}

By

Marion Licher Reyes, RN

Spring 2004

First Advisor: Chia-Ling Mao, RN, PhD

Second Advisor: Colleen O'Leary-Kelley, RN, PhD 


\begin{abstract}
The purpose of this study was to investigate the relationship between nurses' spiritual well-being (using the JAREL Spiritual-Well Being Scale) and their perspectives of spiritual care (using the Spirituality and Spiritual Care Rating Scale). Both instruments use Likert-scale ratings. An additional survey obtained general demographic information including an item regarding spirituality in nursing in-service participation. A total of 130 registered nurses (23\%) participated in the study. The data was analyzed using SPSS in which a Pearson's r correlation was performed on the JAREL and SSCRS scores. The results were statistically significant for a positive correlation between nurses' spiritual well-being and perspectives of spiritual care $(r=$ $0.43, \mathrm{p}<.01$ ) demonstrating that a portion of the nurses' spiritual care perspectives can be attributed to their spiritual well-being. The results underscore the need for academic and postprofessional spirituality training for nurses as well as collaboration of the health care team and administrative support.
\end{abstract}

Keywords: spirituality, spiritual care, spiritual well-being, spiritual care education 


\author{
Investigating the Correlation Between Nurses' \\ Spiritual Well-Being and Spiritual Care Perspectives
}

Prior research suggests that the provision of spiritual care is dependent upon nurses' personal spiritual self-awareness (Cavendish et al., 2004). In addition, nurses' spiritual perspectives influence the type of spiritual care they provide their patients (Brush \& Daly, 2000). This study examines whether a state of spiritual well-being (intact spiritual integrity) is more likely to result in the recognition of spiritual caregiving behaviors. Compromised spiritual integrity may result in the clinicians' inability to recognize impaired spiritual well-being in patients or confuse spiritual distress with other ailments.

Nursing is a holistic, caring profession in which a person's life is viewed as an integrated whole. A prominent feature of holistic care is the interdependence of the spiritual, psychological, and physical dimensions of human beings (Jackson, 2004). A patient's compromised spiritual integrity may negatively influence the physical body as manifested by illness. Patients receive inadequate care when nurses neglect patients' spiritual needs. It would be erroneous to assume that nurses intrinsically possess the knowledge base to offer appropriate spiritual care interventions (Cavendish et al., 2004).

Research Problem

The purpose of this study is to investigate whether nurses' current state of spiritual wellbeing affects their recognition and implementation of spiritual caregiving behaviors. Spirituality in nursing research is vital in enabling the nursing profession to remain equipped to respond to the whole person when treating a patient. Within nursing, this holistic approach of caring for the patient's body, mind, and spirit is synonymous with spirituality (Henery, 2003). The literature also indicates the effect spiritual perspectives have on spiritual care. But does a nurse's spiritual 
well-being affect his/her perspectives on spiritual care interventions? Is the spiritual well-being of nurses related to the spiritual care they provide? It is expected that compromised spiritual integrity may result in deficient spiritual care as evidenced by an inability to identify spiritual care interventions. This research examines how nurses' current state of spiritual well-being relates to their attitudes towards spirituality and their spiritual care interventions.

For the purposes of this study, spirituality is defined as finding meaning and purpose in life (Bradshaw, 1997) by establishing and maintaining intrapersonal (with oneself), interpersonal (to others/environment), and transpersonal (to a higher power/ultimate authority) connections (Reed, 1992). This inclusive definition recognizes an individual as spiritual without necessarily being religious as not all individuals are religious. However, Bradshaw (1997) points out that for many individuals their attitude toward spirituality is influenced by "high levels of belief in....the ordinary God (p.55)." Spiritual well-being is a person's experience of wholeness within the self, other human beings, and in transcendence with another realm (Reed, 1992). Spiritual care is defined as a specific set of practices a nurse undertakes to meet the spiritual needs of patients, such as helping a patient find meaning during an illness or enabling the practice of religious rituals during hospitalization (McSherry, Draper, \& Kendrick, 2002).

\section{Literature Review}

The importance of addressing a patient's spiritual well-being has been referred to in the literature for decades (Brush \& Daly, 2000; Cavendish et al., 2004; Emmer \& Browne, 1984; Hungelman, Kenkel-Rossi, Klassen, \& Stollenwerk 1996; Reed, 1992, Soeken \& Carson, 1986). In fact, Florence Nightingale in the early $20^{\text {th }}$ Century stressed the need to address the patient's physical needs as well as his/her psychological and spiritual needs (Dossey \& Dossey, 1998). 
In 1998 The World Health Organization revised its definition of health as not merely the absence of disease, but rather a state of well-being within four specific domains: physical, mental, social, and spiritual (Cavendish et al., 2004). In addition, the spirituality of a person has been regarded as the most fundamental, basic component of humanness as it relates to health and well-being (Reed, 1992). Despite this awareness, spirituality tends to be ignored in both the nursing curriculum and the clinical setting (Catanzaro \& McMullen, 2001). Each individual has spiritual needs, whether or not they are considered religious. Spiritual integrity is a vital component in the ability to respond appropriately in stressful situations and cope with crises (Shih, Gau, Mao, Chen, \& Lo, 2001). Ultimately, a patient's health is affected by their spiritual well-being (Hungelman et al., 1996). Grant (2004) found that spiritual care interventions benefited the patients with a sense of inner peace, self-awareness, and reduced pain. In fact, neglecting to address and treat patients' spiritual needs may incite feelings of distress (Jackson, 2004) and may actually discourage them from seeking treatment (Sawatzky \& Pesut, 2005). Appropriate spiritual care interventions will result in more desirable patient outcomes and improved overall cost-effectiveness (Brush \& Daly, 2000).

Many authors concede that there is global ambiguity regarding any precise definitions of spirituality, spiritual well-being, and spiritual care (Brush \& Daly, 2000; Cavendish et al., 2004; Fawcett \& Noble, 2004; Grant, 2004; McSherry \& Cash, 2004; Narayanasamy \& Owens, 2001; Pesut, 2003; Treloar, 2000). The challenge lies in the lack of empirical evidence in defining spirituality and spiritual care (McSherry \& Cash, 2004) which may be due, in part, to its hazy nature (Oldnall, 1995) and the fact that spirituality is quite subjective (McSherry \& Ross, 2002). This is further complicated by the dependence of caregiving practices upon nurses' own understanding of spiritual care (Sawatzy \& Pesut, 2005). These realizations make it essential for 
nurses to become educated and trained in the assessment of spiritual distress and in the provision of adequate spiritual care for patients. General themes of spirituality permeate the literature as opposed to precise definitions. Such variegated views may contribute to the challenge of making spirituality a consistent part of the nursing assessment, yet they also create an opportunity for ongoing exploration and dialogue on this important and evolving area of nursing practice.

Spirituality is not measurable, but rather a broad concept (Reed, 1992). The Hebrew word for spirit is recognized as the life force within a person that motivates action (Goldberg, 1998). Spirituality is considered the empowering process of creating meaning out of life situations (especially stressful ones) by relating to dimensions that transcend the self (Reed, 1992). These dimensions include various levels of connectedness intrapersonally, interpersonally, and transpersonally. Spirituality also reveals the development of an individual's value and belief system (Shih et al., 2001). Many consider spirituality to be synonymous with religion and religious practice and spirituality has been coupled with better health outcomes (Goldberg, 1998). However, for many individuals, religiosity is only one part of their spirituality as a whole. Spirituality is also a person's pursuit of inspiration, meaning, and purpose during all occasions in one's life but especially while undergoing emotional stress, illness; or when facing death (Fawcett \& Noble, 2004). Spirituality extends beyond religion making it a key element of health and well-being for the individual (Treloar, 2000).

Healthy spiritual integrity is a person's sense of wholeness and the harmonious balance between oneself and the universe (Hungelman et al., 1996). Spiritual care involves transpersonal caring for the patient; that is, a behavior that communicates to the patient that their beliefs and practices are important and have value. This interaction is mutually beneficial for the patient and the nurse when connecting universal human experiences (Hoover, 2002). On a very fundamental 
level, spiritual care can be woven into all aspects of patient care, be reduced to such basic concepts as love, hope, and compassion (Sawatzky \& Pesut, 2005) and can be implemented with such fundamental interventions as therapeutic use of self and touch (Lo \& Brown, 1999).

Spiritual well-being is associated with health benefits and improved quality of life. Studies reveal positive outcomes for the patient, family, and even the nurse as a result of effective spiritual care. Patients expressed perceptions of inner peace and mindfulness of self, including reports of reduced pain, restored health, and improved recovery from illness (Coyle, 2002; Grant, 2004). Families reported feeling appreciative and possessing a sense of comfort, and the nurses came away with rewarding experiences of spiritual caregiving (Narayanasamy \& Owens, 2001). Nurses' disregard of their own spirituality may be a contributing factor to their uneasiness in addressing the spiritual well-being of their patients (Jackson, 2004) as well as their feelings of inadequacy and ill-preparedness related to spiritual assessments (Brush \& Daly, 2000).

The improper provision or absence of spiritual care can have detrimental consequences. Spiritual distress that remains untreated or misdiagnosed can ultimately result other illnesses, such as clinical depression (McEwan, 2004). Without proper spiritual care training, clinicians who themselves have compromised spiritual integrity will find it difficult to distinguish a patient experiencing spiritual pain from one undergoing psychological pain (McEwan, 2004). The omission of spiritual care has been attributed to a myriad of causes such as limited administrative support and a lack of academic and post-professional training in spiritual care (Narayanasamy \& Owens, 2001; Tanyi, 2002). Establishing working conditions that encourage spiritual care by ensuring adequate time and staffing are forms of administrative support (van Leeuwen \& Cusveller, 2004). The appropriate working conditions afford the nurse opportunities to reflect on 
the process and participate in spiritual training workshops, which contribute to the development of their spirituality (Jackson, 2004). Clergy are frequently sought after as key contributors in dealing with patients' spiritual distress, yet the nurse remains the most readily available individual, especially to hospitalized patients (Highfield, 1992). This should not discount the value of collaborating with hospital chaplains or religious ministers (Bradshaw, 1997; McSherry \& Ross, 2002). The emphasis needs to be on a multidisciplinary approach when caring for patients, realizing nurses require training in the referral process when collaborating with clergy (Ross, 1996).

Cavendish et al. (2004) iterate the adequacy and the sense of spiritual care competence nurses experienced after participating in a spirituality education seminar. They indicate that spiritual care can be learned and should therefore be included in the nursing curriculum as well as professional nursing education. Lo and Brown (1999) maintain that nurses' addressing their own spiritual needs will enable them to understand the significance of spiritual well-being in patients. Meyer's (2003) study on students' perceptions of their ability to provide spiritual care indicated that it was linked to their personal spirituality. In addition, Soeken and Carson's (1986) study indicated nursing students with healthier spiritual well-being viewed spiritual care positively. Cavendish et al. (2004) cite the positive correlation that exists between nurses' spiritual care interventions and the spiritual education they received.

\section{Conceptual Framework}

The conceptual framework that guided this research is The Wellness Model (Figure 1) developed by Adams, Bezner, Drabbs, Zambarano, \& Steinhardt (2000). This model focuses on the perceptions of individuals, because perceptions refine incoming stimuli for interpretation and also affect behavioral responses. 
The Wellness Model includes six dimensions to health: physical, social, psychological, intellectual, emotional, and spiritual. This model is the framework for this study because it incorporates the spiritual aspect of health along with the other more common dimensions, such as physical and emotional health. Taking this concept one step further toward an interpersonal aspect, nurses' spiritual wellness has an impact on the spiritual care they provide.

Adams et al. (2000) address the effect spirituality has on illness. These dimensions are dynamic, in that they are always seeking a state of balance. Illness in the model is defined as perceived disconnection, physical ill-health, feelings of despair, or a blend thereof. The model situates the six dimensions of health and wellness on the surface of a cone, and illness at the bottom-most point of the cone. The researchers suggest a constant, vertical movement in the cone between wellness and illness. Simultaneously, there exists horizontal movement among the six dimensions as a result of constant searching for balance and homeostasis. Any of the six dimensions of wellness has the ability to influence any other dimension of wellness.

The researchers use the example of "extreme wellness conditions" (p. 166) where an increase in one or more wellness dimensions positively affects other dimensions. An example is the way in which sound spiritual wellness can positively influence physical and psychological wellness. Conversely, illness can result in the contraction of one of the wellness dimensions causing a change in other dimensions. This change causes the dimensions to compensate for the compromise in the integrity of the individual's health and well-being.

\section{Methodology}

This research study used correlation analysis on quantitative data by examining the relationship between two variables: spiritual well-being and spiritual care perspectives. The target population was California registered nurses. A randomly selected sample from nine 
Northern and Southern California counties was used. The respondents' names and addresses were obtained from a mailing list provided by the California Board of Registered Nurses. Upon Institutional Review Board approval, 575 subjects were mailed an information packet that included a cover letter briefly describing the study, a consent letter, and a 3-part survey. The respondents were invited to complete the 3-part survey anonymously and mail their responses in a pre-addressed, stamped envelope. A total of 136 nurses responded with six surveys having omitted part 2 of the survey leaving $\mathrm{N}=130$ (23\% response rate). The omission was most likely due to an oversight on the respondents' parts as part 2 appeared on the reverse side of part 1 of the questionnaire.

Part 1 of the survey was The JAREL Spiritual Well-Being Scale (JAREL), which measured spiritual well-being in the nurse (Hungelman et al., 1996). This instrument is a 21 -item Likert scale questionnaire and addresses three dimensions: faith/belief, life/self-responsibility and life satisfaction/self-actualization. The responses ranged from strongly agree (6 points) to strongly disagree (1 point) with seven questions reversed scored. A higher score indicates a healthier state of spiritual well-being. The authors report test-retest reliability of $r=0.88$ as well as content validity.

Part 2 of the survey measured nurses' perspectives on spiritual care by using the Spirituality and Spiritual Care Rating Scale (SSCRS) (McSherry et al., 2002). This instrument is a 17-item Likert scale questionnaire and encompasses 4 factors: spirituality, spiritual care, religiosity, and personalized care. For the purposes of this study, scores were tabulated only from Factor II-Spiritual Care items in order to focus on the nurses' ability to recognize spiritual care behaviors. This subscale consisted of five items and responses ranged from strongly disagree (1 point) to strongly agree (5 points), with no reversed scored items. A higher SSCRS score 
represents a higher degree of spiritual caregiving perspectives. The authors report reasonable internal consistency and a reliability coefficient of 0.64 . The third and final portion of the survey collected general demographic information (Table 2). An additional item regarding the nurses' participation in a spirituality in nursing in-service was also included.

Data Analysis

Data analysis was conducted using Statistical Package for Social Sciences (SPSS) software. The sample consisted of 115 female and 10 male registered nurses (5 blank) from nine Northern and Southern California counties. The mean scores of the JAREL and SSCRS scales were 103 and 22 respectively. The majority of the respondents (77\%) did not participate in any spirituality in nursing in-service while $20 \%$ responded Yes, $2 \%$ were Uncertain, and $<1 \%$ left the item blank. The Pearson's r correlation coefficient was used to examine the relationship between nurses' spiritual well-being as measured by the JAREL Spiritual Well-Being Scale and spiritual caregiving perspectives as measured by the Spirituality and Spiritual Care Rating Scale. The results demonstrate a statistically significant positive correlation value between spiritual wellbeing and spiritual care perspectives as evidenced by a Pearson's correlation of $r=0.43$ at a significance level of $p<.01$ (2-tailed).

\section{Discussion}

Further research is warranted as this study is limited by the low percentage of survey responses. This may be due in part to the lengthy questionnaire encompassing three parts to the survey. A larger sample size will offer greater generalizability. This study was limited to nine California counties in metropolitan areas of Northern and Southern California. Further studies are recommended on a more representative sample of a larger geographic area with diverse demographics for data comparison. 
Spirituality has an undeniable link to health and quality of life. The results of this study indicate a statistically significant positive correlation between JAREL and SSCRS scores. That is, nurses' spiritual well-being is positively correlated to spiritual caregiving perspectives. Administrative support in the workplace by providing adequate staffing and permitting ample time to incorporate spirituality assessments will provide ongoing opportunities for the implementation of spiritual care. These opportunities will help to foster nurses' personal spiritual awareness and spiritual well-being. Professional in-services and academic curricula that include spirituality can help nurses and nursing students achieve and/or maintain spiritual integrity, which will enhance their ability to provide spiritual care. Proper education and training in spirituality will produce nurses who feel prepared and confident to appropriately address the spiritual needs of patients.

\section{Conclusion}

Addressing patients' spiritual needs is not an option left to the discretion of the nurse, but rather an essential component in all aspects of caregiving. The establishment of effective and appropriate spiritual care interventions is contingent upon the awareness of the nurse's personal spirituality. There is no denying the pronounced impact spirituality has on health. This paper has demonstrated the varied health ailments patients experience when their spiritual needs are neglected including feelings of distress and physical illness. A multifaceted approach is necessary to meet the challenge of fostering nurses' spiritual well-being. Curricula change, professional in-service education, administrative support, and interdisciplinary collaboration have been suggested in overcoming obstacles of spiritual care and the nurturing of nurses' spiritualilty. Including spirituality in physical, social, and psychological assessments will render nursing care truly holistic and improve the quality of nursing interventions and patient outcomes. 


\section{References}

Adams, T. B., Bezner, J. R., Drabbs, M. E., Zambarano, R. J., \& Steinhardt, M. A. (2000). Conceptualization and measurement of the spiritual and psychological dimensions of wellness in a college population. Journal of American College Health, 48, 165-173.

Bradshaw, A. (1997). Teaching spiritual care to nurses: An alternative approach. International Journal of Palliative Nursing, 3, 51-57.

Brush, B. L., \& Daly, P. R. (2000). Assessing spirituality in primary care practice: Is there time? Clinical Excellence for Nurse Practitioners, 4, 67-71.

Catanzaro, A. M., \& McMullen, K. A. (2001). Increasing nursing students' spiritual sensitivity. Nurse Educator, 26, 221-226.

Cavendish, R., Luise, B. K., Russo, D., Mitzeliotis, C., Bauer, M., Bajo, M. M., Calvino, C., Horne, K., \& Medefindt, J. (2004). Spiritual perspectives of nurses in the United States relevant for education and practice. Western Journal of Nursing Research, 26, 196-212.

Coyle, J. (2002). Spirituality and health: Towards a framework for exploring the relationship between spirituality and health. Journal of Advanced Nursing, 37, 589-597.

Dossey, B. M., \& Dossey, L. (1998). Attending to holistic care. American Journal of Nursing, 98, 35-38.

Emmer, R., \& Browne, P. (1984). Program helps nurses develop spiritual care skills. Hospital Progress, 2, 64-66.

Fawcett, T. N., \& Noble, A. (2004). The challenge of spiritual care in a multi-faith society experienced as a Christian nurse. Journal of Clinical Nursing, 13, 136-142.

Goldberg, B. (1998). Connection: An exploration of spirituality in nursing care. Journal of Advanced Nursing, 27, 836-842. 
Grant, D. (2004). Spiritual interventions: How, when, and why nurses use them. Holistic Nursing Practice, 18, 36-41.

Henery, N. (2003). Constructions of spirituality in contemporary nursing theory. Journal of Advanced Nursing, 42, 550-557.

Highfield, M. F. (1992). Spiritual health of oncology patients. Cancer Nursing, 15(1), 1-8.

Hoover, J. (2002). The personal and professional impact of undertaking an educational model on human caring. Journal of Advanced Nursing, 37, 79-86.

Hungelman, J., Kenkel-Rossi, E., Klassen, L., \& Stollenwerk, R. (1996). Focus on spiritual well-being: Harmonious interconnectedness of mind-body-spirit-Use of the JAREL Spiritual Well-Being Scale. Geriatric Nursing, 17, 262-266.

Jackson, J. (2004). The challenge of providing spiritual care. Professional Nurse, 20, 24-26.

Lo, R., \& Brown, R. (1999). Holistic care and spirituality: Potential for increasing dimensions of nursing. The Australian Journal of Holistic Nursing, 6, 4-9.

McEwan, W. (2004). Spirituality in nursing: What are the issues? Orthopaedic Nursing, 23, 321326.

McSherry, W., \& Cash, K. (2004). The language of spirituality: An emerging taxonomy. International Journal of Nursing Studies, 41, 151-161.

McSherry, W., Draper, P., \& Kendrick, D. (2002). The construct validity of a rating scale designed to assess spirituality and spiritual care. International Journal of Nursing Studies, 39, 723-734.

McSherry, W., \& Ross, L. (2002). Dilemmas of spiritual assessment: Considerations for nursing practice. Journal of Advanced Nursing, 38, 479-488.

Meyer, C. L. (2003). How effectively are nurse educators preparing students to provide spiritual 
care? Nurse Educator, 28, 185-190.

Narayanasamy, A., \& Owens, J. (2001). A critical incident study of nurses' responses to the spiritual needs of their patients. Journal of Advanced Nursing, 33, 446-455.

Oldnall, A. S. (1995). On the absence of spirituality in nursing theories and models. Journal of Advanced Nursing, 21, 417-418.

Pesut, B. (2003). Developing spirituality in the curriculum: Worldviews, intrapersonal connectedness, interpersonal connectedness. Nursing Education Perspectives, 24, 290 294.

Reed, P. G. (1992). An emerging paradigm for the investigation of spirituality in nursing. Research in Nursing \& Health, 15, 349-357.

Ross, L. A. (1996). Teaching spiritual care to nurses. Nurse Education Today, 16, 38-43.

Sawatzky, R., \& Pesut, B. (2005). Attributes of spiritual care in nursing practice. Journal of Holistic Nursing, 23, 19-33.

Shih, F., Gau, M., Mao, H., Chen, C., \& Lo, C. K. (2001). Empirical validation of a teaching course on spiritual care in Taiwan. Journal of Advanced Nursing, 36, 333-346.

Soeken, K. L., \& Carson, V. J. (1986). Study measures nurses' attitudes about providing spiritual care. Health Progress, 67, 52-55.

Tanyi, R. A. (2002). Towards clarification of the meaning of spirituality. Journal of Advanced Nursing, 39, 500-509.

Treloar, L. L. (2000). Integration of spirituality into health care practice by nurse practitioners. Journal of the American Academy of Nurse Practitioners, 12, 280-285.

van Leeuwen, R., \& Cusveller, B. (2004). Nursing competencies for spiritual care. Journal of Advanced Nursing, 48, 234-246. 
Figure 1

The Wellness Model

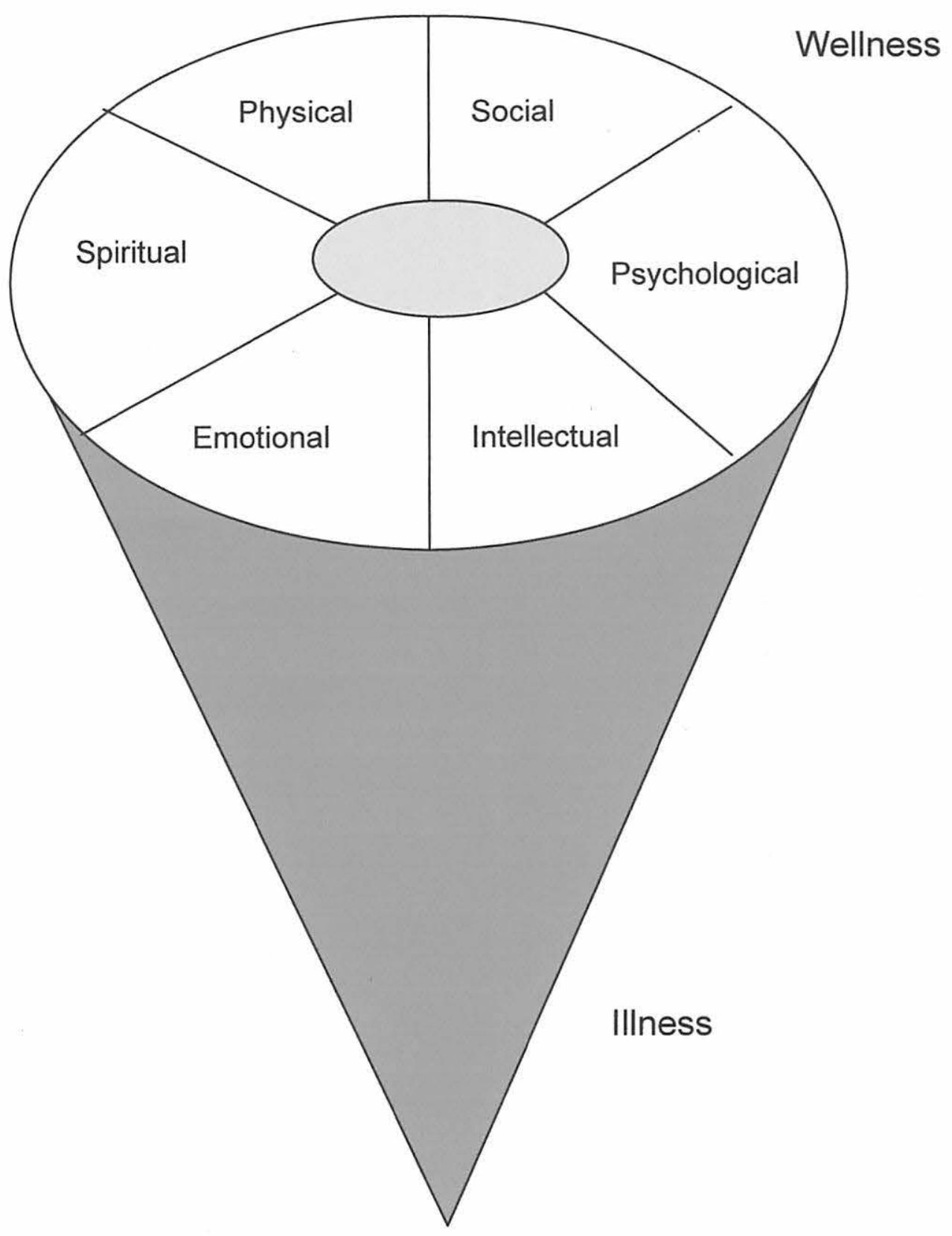

A conceptual model of health and wellness. The 6 dimensions to health include social, psychological, intellectual, emotional, spiritual, and physical well-being; they are dynamic and seek a state of balance. Illness is a perceived disconnection, physical ill-health, or feelings of despair. Any dimension of wellness has the ability to influence another dimension of wellness. 
Table 1

Descriptive Statistics and Correlation Results of the JAREL Spiritual Well-Being Scale and the Spirituality and Spiritual Care Rating Scale.

\begin{tabular}{|c|c|c|c|}
\hline Scale & Mean (SD) & Range & Pearson's r Correlation \\
\hline JAREL & & & \\
$(\mathrm{N}=30)$ & $103 \pm 12.77$ & $63-126$ & $\mathrm{r}=.43$ \\
\hline SSCRS & & $\mathrm{p}<.01$ \\
$(\mathrm{~N}=30)$ & $22 \pm 2.22$ & $16-25$ & \\
\hline
\end{tabular}


Table 2

Demographic and spiritual characteristics of the sample

\begin{tabular}{|c|c|}
\hline Variable & $\mathrm{n}(\%)^{*}$ \\
\hline \multicolumn{2}{|l|}{ Gender } \\
\hline Male & $10(8)$ \\
\hline Female & $115(88)$ \\
\hline \multicolumn{2}{|c|}{ Highest Nursing Degree Earned } \\
\hline Diploma & $17(13)$ \\
\hline $\mathrm{ADN}$ & $37(28)$ \\
\hline BSN & $59(45)$ \\
\hline Master's & $14(11)$ \\
\hline Doctorate & $1(<1)$ \\
\hline \multicolumn{2}{|l|}{ Religious Affiliation } \\
\hline Yes & $91(70)$ \\
\hline No & $20(15)$ \\
\hline \multicolumn{2}{|l|}{ Spirituality In-service } \\
\hline Yes & $26(20)$ \\
\hline No & $100(77)$ \\
\hline Uncertain & $3(2)$ \\
\hline
\end{tabular}

\begin{tabular}{|c|c|}
\hline Variable & $\mathrm{n}(\%)^{*}$ \\
\hline \multicolumn{2}{|l|}{ Nursing Specialty } \\
\hline Community/Public Health & $4(3)$ \\
\hline Medical/Surgical & $18(14)$ \\
\hline Perioperative & $14(11)$ \\
\hline Critical Care Units & $10(7)$ \\
\hline Emergency & $9(7)$ \\
\hline L\&D/OB/GYN & $8(6)$ \\
\hline Home Care & $5(4)$ \\
\hline Faculty & $3(2)$ \\
\hline Oncology & $2(1)$ \\
\hline Psychiatric & $5(4)$ \\
\hline Pediatrics & $5(4)$ \\
\hline Maternal/Child & $2(1)$ \\
\hline Orthopaedics & $2(1)$ \\
\hline Combined Specialties & $21(16)$ \\
\hline Other & $17(17)$ \\
\hline
\end{tabular}

*Percentages do not total 100 due to blank items. 